\title{
Research Article \\ Research on the Construction of an e-Commerce Marketing System Based on the Wireless Sensor Network
}

\author{
Chi Zhang \\ Huanghuai University, Zhumadian 463000, China \\ Correspondence should be addressed to Chi Zhang; 20121261@huanghuai.edu.cn
}

Received 24 September 2021; Accepted 13 October 2021; Published 8 December 2021

Academic Editor: Guolong Shi

Copyright ( 2021 Chi Zhang. This is an open access article distributed under the Creative Commons Attribution License, which permits unrestricted use, distribution, and reproduction in any medium, provided the original work is properly cited.

\begin{abstract}
This paper takes e-commerce as the research object, based on the combination of wireless sensor network research results, using relevant theoretical analysis tools to identify several major problems in the marketing of enterprises. Then, the internal environment conditions of developing e-commerce are comprehensively analyzed through human resources, financial resources, marketing ability, and platform building ability, and the advantages and disadvantages of the enterprise itself are presented in a three-dimensional manner to help the enterprise understand its situation. Firstly, the overall hardware structure design of this paper is analyzed, and the network marketing node hardware design is proposed as the core of the system hardware design, and the marketing node hardware design circuit diagram is given through the selection of marketing node sensors, the selection of wireless communication modules, and the selection of marketing node microprocessors. Based on the specific application of the wireless sensor network in the e-commerce marketing system, the number of cluster selection is reduced by calculating and setting the remaining energy threshold of the cluster head for the whole network. The optimal cluster head is searched for based on the density of marketing nodes in different regions and the minimum energy consumption of the cluster after the division of the region within the cluster, and the original cluster head is replaced; the density of marketing nodes in different e-commerce is different, and the optimal number of cluster heads is searched for based on the minimum energy consumption of the network. In summary, three strategies are implemented to improve the design of wireless sensor network routing, and the effectiveness of the algorithm is verified through experimental simulation. Through the analysis of e-commerce operation, the intracluster congestion control is achieved by a dual-cluster head strategy with intracluster push selection of subcluster heads; the network nonuniform hierarchy and resource scheduling strategy achieve intercluster congestion mitigation and decongestion. A minimum energy consumption multihop path tree is also proposed here, which can achieve the lowest energy consumption of marketing nodes and networks and improve the link quality relative to other transmission paths. After simulation experiments, the effectiveness and reliability of the congestion algorithm are verified. A guarantee scheme is provided for the development of e-commerce marketing strategies to help breakthroughs and developments in marketing management, and an attempt is also made to provide a template for other enterprises to follow.
\end{abstract}

\section{Introduction}

The rapid development of network information technology has led to the emergence of new dynamics of e-commerce in social and economic development and made the new normal of economic development into a network economy [1]. The main manifestation of network economy is ecommerce; under the development of network economy, the real economy has more severe challenges, companies in all walks of life need to analyze their marketing environment, and marketing space and marketing model, to promote their adaptability, survival, and development capabilities in the new economic environment, can be improved. There are a large number of sensor marketing nodes inside the network of wireless sensor networks, whose locations are relatively stationary in general, but not necessarily fixed and dynamic in special circumstances; these sensors are either at rest or on the move, and they are often deployed in harsh environments or enemy areas that are difficult to secure by manual means. They work cooperatively to acquire, collect, process, and transmit information about the territory or object of study, and to send this information to network users [2]. 
The external environment in which the marketing nodes are located has various uncontrollable factors that can change at any time, such as temperature and humidity changes, wind and pressure fluctuations, etc. Because of these external factors, the sensor marketing nodes are vulnerable to attacks that can damage and fail, resulting in anomalies or even paralysis of the entire network [3]. For example, when the sensor marketing nodes are deployed in the enemy's military area, it is easy to be discovered by the enemy and thus captured by the enemy, which will cause the leakage and tampering of our data, and the network may even appear in the enemy's disguised marketing nodes; sensor marketing nodes deployed in the field in the harsh natural areas, the impact of the environment, and the internal modules of the marketing nodes are prone to failure, which will lead to network errors [4].

Led by the concept of big data, based on the urgent demand of e-commerce for big data collection in the sales process and combined with the e-commerce operation status, we choose a wireless sensor network as the data collection technology in the e-commerce sales process to realize the collection, processing, and transmission of commodity data in e-commerce and prepare for the subsequent data analysis and data mining. In this paper, we introduce wireless sensor network technology, wireless communication technology, database technology, and data mining technology into e-commerce sales systems [5]. The wireless sensor network is a low-power, low-cost, low data transmission rate and has a new technology of data acquisition, transmission, and processing, which can achieve real-time positioning and dynamic monitoring of static and dynamic sensor marketing nodes in the target area. Therefore, wireless sensor networks in the military field, urban intelligent transportation systems, ecological agriculture, smart cities, electronic intelligence, industrial production, and other fields to get more brand new applications, and the prediction of industrial optimization and upgrading direction to provide theoretical and data support for the transformation and upgrading of enterprises, product innovation, promote social development, provides very efficient development of power and direction [6]. Through the use of scientific theoretical analysis tools, it provides a comprehensive analysis of the current situation of e-commerce operations and marketing and proposes problems exposed in the development of enterprises and rationalization suggestions that can be improved, to help enterprises achieve benign development, and the research results of this paper can be used as reference for other related enterprises in Henan and other regions facing the same problems.

This paper focuses on the research and design of wireless sensor networks to realize the browsing data within the ecommerce marketing system for subsequent data processing and data mining. In the wireless sensor network research, design and construction work, due to the large variety and number of e-commerce goods, distribution density and uneven, through the marketing node hardware design, wireless communication module design, network topology design, and network routing design to achieve the network energy balance reduce network energy consumption and extend the network life cycle of the goal. Combined with the e-commerce sales operation conditions, in the night of the day, the in the night of the week, the weekend of the week, and the seasonal change of the year, there will be a surge of network data collection traffic, which will easily lead to network congestion at the marketing node level and link level, through the research and design of the lowest energy consumption multihop path and wireless sensor network congestion control strategy to achieve network congestion control, save network energy, and improve network quality of service and other network optimization. Then, by designing and creating a database to achieve effective data storage and management and finally by designing a user interface design to achieve human-computer interaction between the e-commerce marketing system and related personnel, Section 1 introduces the development status of e-commerce marketing based on wireless sensor networks and the research background and significance of the project and describes the research content and structure of this paper. Section 2 mainly introduces the status quo of related research and explains the focus of this article through analysis. Section 3 conducts the research on the construction of an e-commerce marketing system based on a wireless sensor network and analyzes the research for the e-commerce marketing system. Section 4 is an analysis of the research results of this paper. Section 5 summarizes all the work of this paper, pointing out the problems still unsolved by the research and the arrangement of future work.

\section{Related Work}

Affected by the mobility of resources, the increasing competition among companies, and the differentiated characteristics of the needs among customers, Ocloo et al. based on the fiercely competitive environment, it is proposed in enhancing competitiveness can be through the construction of a platform strategy, in building the platform, both to strengthen the infrastructure and strategic cooperative alliances. Improving appropriate business processes with management support [7]. The scholar proves in practice that when implementing e-commerce, it is not just about building a platform but should operate all aspects of business processes and improve management. Manohar et al. argue that if they want to improve business operations, they can use Internet technology to give them an advantage in the market and create more profits. To deepen the level of understanding of the market, Internet technology can be used to analyze costs as well as profits in-depth and to understand consumer preferences $[8,9]$. The Internet allows for complex economic activities that can reduce transaction time on the one hand, and will also reduce transaction costs on the other. The scholar suggests that there are several ways in which companies can enhance their self-worth, the main ways include developing entertainment programs, investigating user satisfaction, and the level of feedback [10]. Walsh et al. summarize and analyze a variety of theories oriented to trust in WSNs and find that most trust models start from malicious attack detection, secure routing, secure data aggregation, secure location, and secure marketing node selection 
[11]. By analyzing the degree of response of existing trust models to malicious attacks, several basic trust criteria are obtained and a robust network trust model is proposed [12].

Liu et al. define precision marketing as sending the right message to the right customer at the right time through the right channel, thus truly influencing the target customer's purchase decision and promoting the effective achievement of marketing goals [13]. Yuan et al. believe that ecommerce has become the trend of social development in recent years, and big data has become an essential way to obtain information and plays a pivotal role in different research fields, especially in the business field representing e-commerce. Competition among e-commerce companies has become extremely fierce, which has forced companies to take the initiative to seek cheaper marketing strategies rather than by expanding their market share, and the need for business development has become a source of motivation for e-commerce to introduce big data mining techniques and extract data from e-commerce websites [14]. Personalized marketing is becoming increasingly known and accepted by consumers, and the majority of enterprises will also carry out precision marketing as an important strategy for enterprises, precision marketing helps to play the business advantages of enterprises. But companies lack reasonable tools on how to carry out precision marketing [15]. Although big data strategy provides many analytical methods for companies to carry out precision marketing, big data analysis technology is still monopolized by a few companies [16].

In summary of domestic and foreign research literature, compared with domestic, foreign research theory started earlier and is more mature. Many enterprises have applied the research results in practice, and the research has strong practical significance and can guide enterprises to better use e-commerce. At present, foreign scholars' research has strong practicality and operability, focusing on enterprises' application in practice, which can help enterprises better improve their operation in practice. The focus of research is no longer purely theoretical research, its practice can guide enterprises to develop more consistent with the e-commerce program, more targeted, scholars in the field has been a lot of research results, can guide the organic integration of enterprises and ecommerce. Ensure that the wireless sensor network can continue to provide stable normal services, in the event of abnormalities in the network state can be timely alarm and troubleshooting. Keeping abreast of wireless sensor network operation and timely detection of security threats can provide a basis for network maintenance personnel to take effective countermeasures, thereby improving wireless sensor network security. This paper is dedicated to establishing an accurate and efficient wireless sensor network security situational awareness system to help network maintenance personnel grasp the health status of wireless sensor network operation in real-time and provide accurate, intuitive, and quantitative security indicators for network maintenance personnel when the network is under attack or other security threats.

\section{Research on the Construction of e- Commerce Marketing System Based on the Wireless Sensor Network}

3.1. Wireless Sensor Network Marketing Model. The information transmitted in the network is the carrier of mutual communication between sensor marketing nodes, and different types of information represent different behaviors of marketing nodes. By tracking multiple combinations of behaviors of marketing nodes in a period, we can grasp the state changes of marketing nodes in that period, and then analyze the state changes of sensor marketing nodes in the network to obtain the overall changes of the network in that period [17]. The security situational awareness model based on set pair analysis calculates the situational characteristics of the marketing nodes by collecting the feature vector attributes of the operation of the sensor marketing nodes in the network, and then analyzes the trend of the changes in the characteristics of the marketing nodes in the network to derive the overall operational situational characteristics of the network, calculates the operational situational characteristics of the system to be tested and the security situational bribe concerning the system characteristics, and derives the security situational values of the network to be tested, and the flow of situational awareness The process of situational awareness is shown in Figure 1.

The sending rate factor is an attribute used to measure how many packets are generated and sent by wireless sensor marketing nodes per unit time [18]. Let $f(m, t)$ be the number of self-generated packets sent by marketing node $\mathrm{m}$ in period t. The $f(m, t)$ is relatively fixed in a data collection wireless sensor network in a stable state, and if $f(m, t)$ is much larger than the average value of $f(t)$ of marketing nodes in the network, there is suspicion that marketing node $k$ launches a DOS attack; if $f(m, t)$ is much smaller than the average value of $f(t)$ of marketing nodes in the network, there is a suspicion that marketing node $m$ is attacked by a black hole or the marketing node fails. The definition of the mathematical expression of the sending rate factor can be expressed as

$$
f(m, t)=\frac{n * f(m, t)}{\sum_{i=1}^{n} f(i, t)}
$$

The forwarding rate factor is an attribute that measures the level of forwarding packets by the wireless sensor marketing node. Let $k(i, t)$ be the number of packets received by marketing node $m$ in period $t$ and $h(m, t)$ be the number of forwarded packets sent by marketing node $m$ in period $t$. If $g(m, t)$ is much larger than the average value of $h(t)$ of marketing nodes in the network, there is a suspicion that marketing node $m$ launches a black hole attack. The definition of the mathematical expression for the forwarding rate factor can be expressed as

$$
g(m, t)=\frac{n *(h(m, t) / k(i, t))}{\sum_{i=1}^{n} h(i, t) / k(i, t)} .
$$




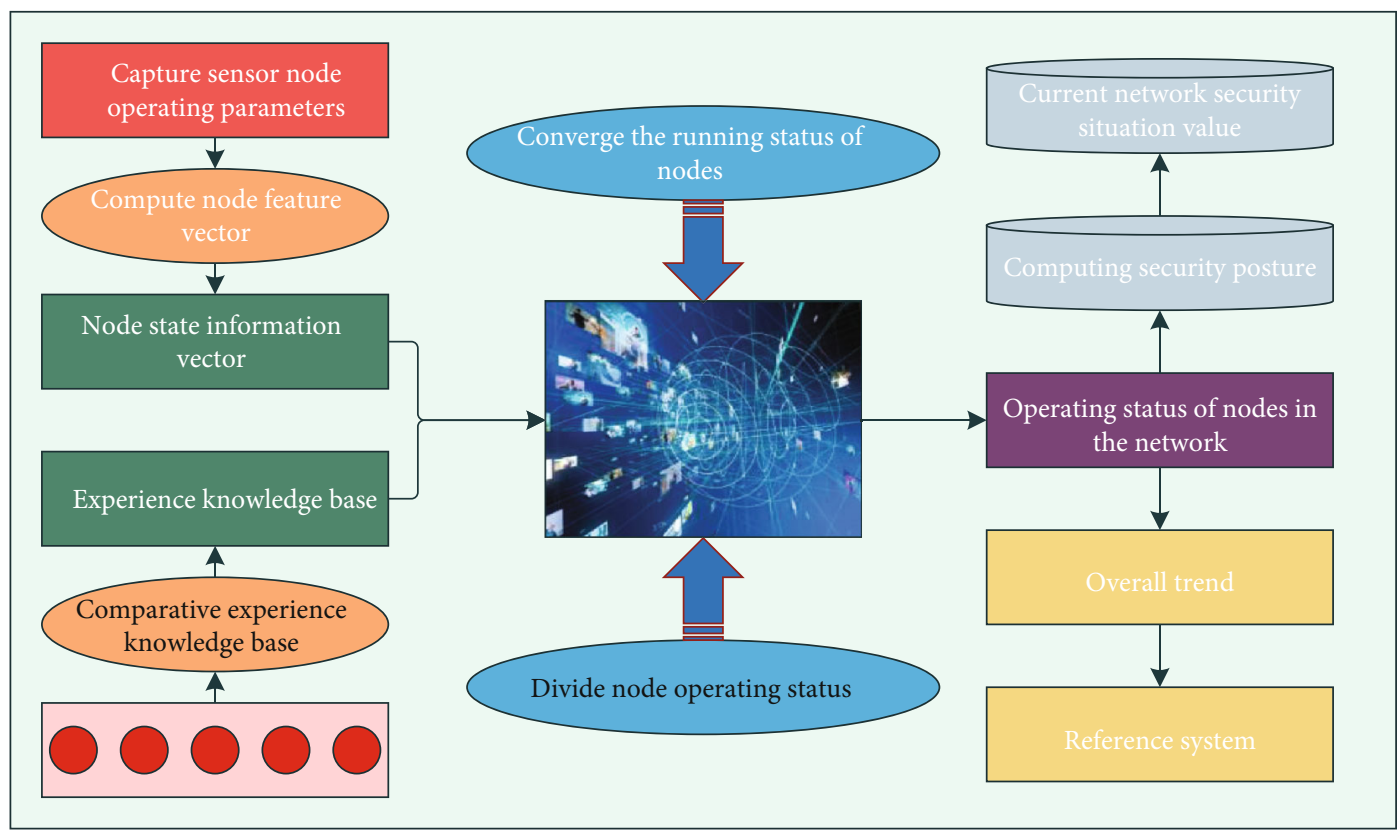

FIGURE 1: The basic process of WSN security situational awareness.

The data source dispersion rate factor is an attribute that measures the degree of dispersion of the data source. Let $L$ $(m, t)$ be the number of neighboring marketing nodes contained in the first $n$ packets to which marketing node $m$ arrives and $N$ be the total number of marketing nodes [19] An excessive number of $l(m, t)$ is suspected of marketing node $m$ launching a witch Sybil attack, Wormholes attack, or other link failures. The definition of the mathematical expression for the data dispersion rate factor can be expressed as

$$
L(m, t)=\frac{l(m, t)}{N}
$$

The sensor marketing node records and discriminates the incoming and outgoing packets in period $t$. The data information vector passing through the sensor marketing node in period $t$ is denoted by $L=\left(l_{1}, l_{2}, l_{3} \cdots, l_{n}\right)$. The data information vector $D$ is compared with the feature information vector set $M=\left[M_{1}, M_{2} \cdots, M_{l}\right\}$, to form a homogeneous inverse system. Let the degree of connection between $D$ and $M_{l}$ on the $x$ th component be $u(x, t)$. According to the set pair analysis theory, the homogeneous inverse expression of this system is expressed as

$$
u(x, t)=a(x, t)+b(x, t)+c(x, t)
$$

where $u(x, t)$ denotes the degree of identity between the data information vector $D$ and the feature information vector $M_{m}$ on the $x$ th component, and a larger value indicates a higher degree of similarity between the two information; $b(x, t)$ denotes the degree of dissimilarity between the two components, and a larger value indicates a higher degree of uncertainty between the two information; and $c(x, t)$ denotes the degree of opposition between the two components, and a larger value indicates a higher degree of opposite information. The $x$ th component vector is a continuous-type variable; then, the set pair potential of vector $D$ and vector $M_{m}$ on the $x$ th component vector is defined as.

$$
\psi(x)=\frac{f(x, d)-f(x, m)}{f(x, d)+f(m, d)}
$$

Full coverage probability is the probability of full coverage occurring. According to the full coverage probability formula, the probability of full coverage of wireless sensor network to the monitoring area is related to the distribution density of effective sensor marketing nodes, and the probability of full coverage of the network is larger when the density of marketing nodes distributed in the monitoring area is larger, and conversely, the probability of full coverage of the network decreases when the distribution density of effective marketing nodes in the monitoring area decreases [20]. It is not easy to measure the distribution density of sensor marketing nodes in the natural environment. Experimentally, it is found that the distribution density of effective marketing nodes in wireless sensor networks is positively correlated with the trend of network security posture, so it is possible to use the value of wireless sensor network security posture to evaluate the distribution density of effective sensor marketing nodes and to classify the degree of network security by the full coverage probability. The full coverage probability expression is in equation (6). $l$ is the monitoring area edge length, used in the sensor marketing node density $\left(w=N / l^{2}\right), N$ is the number of effective sensor marketing nodes in the wireless sensor network, and $\chi$ is the sensor 
marketing node sensing radius.

$$
w(x)= \begin{cases}e^{-\lambda L\left(1+\lambda x^{2}\right),} & w \geq w(x), \\ 0, & w<w(x)\end{cases}
$$

3.2. e-Commerce Marketing System Construction. e-Commerce companies can use big data to analyze the degree of consumer demand, purchasing power, and loyalty, to adopt different pricing strategies. For the more price-sensitive customers to conduct discount promotions, issue coupons or full reductions, for the price is not sensitive to the original price of customer sales, for frequent purchases of regular customers can use exclusive prices. In terms of price system differentiation, the platform does have a lot to learn and learn from, in addition to the common discount prices, coupons, reductions, gifts, there are fan-only prices, member prices, exclusive prices for regular customers, the first single gift [21]. Fan exclusive price, as the name suggests, is to become a fan of the store, usually follow the store can become a fan, by setting a fan exclusive price, you can enjoy the exclusive price, and nonfans are the original price. Member price is to become a member of the store first, the threshold and requirements to become a member are set by the merchant, meet the requirements to become a member. The exclusive price for old customers is the exclusive benefit price for old customers of the store. The first-order bonus is a way for merchants to get new customers and is an exclusive offer for new customers to increase their willingness to buy and promote purchase conversion.

This paper is a wireless sensor network model based on a split-cluster topology, which is very prone to both intracluster cluster head congestion and SINK area cluster head congestion in the case of data volume surge. Through the access to the data of each platform, the use of big data technology to integrate, calculate and analyze the data, more accurately locate the target customers, segment the target customers, and carry out accurate recommendations and differentiated marketing. Preferences, recommend products that they may be interested in or may want to buy, to help users find what they want with as little time and energy as possible; at the same time, through SMS, emails, personalized recommendations, etc., improve marketing effects and increase user stickiness.

The network judges whether it is in a congestion state through cycle congestion detection, if no congestion is detected in the cycle, it enters the next network cycle congestion detection; if congestion trend is detected, the network judges whether it is intracluster congestion or intercluster congestion by the size of $\mathrm{P}$. The network is in intracluster congestion condition, the cluster uses the data traffic congestion control algorithm (COMUT) algorithm idea based on subclustering to get the subcluster head $(\mathrm{VCH})$, the marketing nodes within the cluster choose which cluster head to join and update the marketing node routing table into a cluster according to the principle of minimum energy consumption of communication links, and then judge whether there is intercluster congestion, if there is, then enter the intercluster congestion control link, otherwise detect whether the congestion is lifted. If the network is judged to be in intercluster congestion condition, first the network is nonuniformly hierarchical and the intercluster cluster head establishes LEMPT tree optimization path, then check whether the congestion is relieved and lifted, if not, wake up the marketing node (CM) adjacent to the congested cluster head $(\mathrm{CH})$ with the highest energy and become the cluster head, update LEMPT, then detect whether the congestion is lifted, if not, then enter the congestion control loop, and if the congestion has been lifted, delete the congestion control resource.

We divide the whole network marketing nodes into three degrees of priority, important, secondary, and general, for the marketing node timer randomly select the set value of the region in increasing order, each region is divided as shown in equation (7). $X$ is the set of important marketing nodes, $Y$ is the set of secondary marketing nodes, and $Z$ is the set of general marketing nodes. According to the principle of equation (7), the set value is chosen randomly for each marketing node timer, and if the marketing node data timeout in the marketing node cache queue, the marketing node becomes VCH.

$$
G(x)=\left\{\begin{array}{l}
g(x) *[0, x, 1], x \subset X, \\
g(x) *[x, 1,0], x \subset Y, \\
g(x) *[1,0, x], x \subset Z .
\end{array}\right.
$$

Through the precision marketing big data platform for each user to establish information files, you can fully explore the value of user data, to provide strong support for the implementation of precision marketing strategies. eCommerce companies in the long-term development process, continue to collect key information about users, network interactive trading platform for the integration of user data provides a convenient, with the development of new social media, communication with users also strengthened, the collection contains the basic information of users, consumption habits and preferences and other high-value data, in the context of big data technology, user data can be more in-depth analysis, and mining user behavior patterns and needs and other aspects of more valuable information. In the context of big data technology, user data can be analyzed more deeply to uncover more valuable information about user behavior patterns and needs.

Enterprise products and information is an important basis for the company in building marketing channels, not aware of the importance of customer demand, so enterprise managers cannot get the changes in customer demand promptly. First, the one-way transmission cannot accurately and comprehensively obtain customer information, which greatly reduces the efficiency of enterprise data collection; second, the lack of a market feedback mechanism will lead to the enterprise cannot accurately grasp the market changes and consumer demand development trend, making the enterprise in the price, channels, products and other aspects of competitiveness is far below the local enterprises. 
3.3. e-Commerce Marketing Evaluation. In this paper, according to the characteristics of marketing in the context of e-commerce, marketing concerns, the construction ideas and principles of marketing index evaluation system, based on establishing the framework of marketing evaluation system of marketing in the context of e-commerce, we choose the combination of literature combing and survey visits to design a preliminary marketing evaluation system and continue to carry out an expert questionnaire survey to prove its rationality. Through the expert questionnaire survey, under the premise of ensuring the overall and systematic marketing evaluation system, the marketing evaluation index system is optimized and adjusted according to the expert opinions, and the marketing evaluation index system is finally constructed as shown in Table 1 .

Financial capability indicators have always been in a key position in the evaluation system of marketing of for-profit enterprises, and this is also true for marketing in the context of e-commerce. In this paper, the four aspects of total assets return, total assets turnover, operating income ratio, and current ratio are selected to reflect the level of financial capability of marketing in the context of e-commerce. Reflects the overall profitability of all assets, including net assets and liabilities of e-commerce marketing, and is a key indicator used to assess the profitability of enterprises. Total profits are all profits generated by e-commerce marketing during the cycle. Interest expense is the actual interest on borrowings, bond interest. That e-business marketing spends in its operations. And the average of total business assets out of the cycle and at the end of the cycle is the average total assets. Usually, the return on total assets is positively correlated with the profitability and operating level of the enterprise. RTA is the rate of return on total assets, TP is the total profit, IE is the interest expense, and TA is the average total assets.

$$
\mathrm{RTA}=\frac{\mathrm{TP}+\mathrm{IE}}{\mathrm{TA}} * 100 \%
$$

The total asset turnover ratio, which is the ratio of net sales revenue to the average balance of total assets, is a key indicator to evaluate the ability of e-commerce cold chain logistics assets to operate. If the ratio is low, it indicates the poor operation of the enterprise's assets, which will eventually hinder the profitability of the enterprise and vice versa. TRA represents the turnover rate of total assets, NSR represents net sales revenue, and ATA represents the average balance of total assets.

$$
\mathrm{TRA}=\left(\frac{\mathrm{NSR}}{\mathrm{ATA}}\right) * 100 \%
$$

The revenue growth rate is the ratio of the increase in revenue of the enterprise in this cycle to the total revenue of the previous period, which is an important indicator to evaluate the growth status and development capacity of ecommerce marketing. Usually, the higher the revenue growth rate, indicating faster growth rate of e-commerce marketing, the more promising it is; conversely, when the value is negative, the actual business needs to be adjusted as soon as possible. OGR represents the growth rate of operating income, ITA represents the increase in total operating income in this cycle, and TIP represents the total operating income in the previous cycle.

$$
\mathrm{OGR}=\left(\frac{\mathrm{ITA}}{\mathrm{TIP}}\right) * 100 \% .
$$

The current ratio is the ratio of current assets to current liabilities. It is a key indicator to measure the solvency of ecommerce marketing. Current assets mainly include inventories, receivables and prepayments, marketable securities, cash and noncurrent funds due within the cycle. Current liabilities cover short-term borrowings and noncurrent liabilities due within the cycle. They are also generally expressed as total current liabilities at the end of the period in the current balance sheet. CR stands for current ratio, current assets during the CAR cycle, and CLC stands for current liabilities during the cycle.

$$
\mathrm{CR}=\left(\frac{\mathrm{CAR}}{\mathrm{CLC}}\right) * 100 \% .
$$

The level of customer service capability will not only involve the survival and development of the enterprise, but also the basis for the development and utilization of external resources. Higher customer service capability not only reflects the customer-oriented values of the enterprise but also can in turn improve customer loyalty and win greater market space for the enterprise. This paper evaluates the marketing level of enterprise customer service capability in six aspects, including customer complaint rate, customer complaint handling rate, cold chain delivery on-time rate, cold chain delivery accuracy rate, cold chain logistics service integration degree, and freshness of agricultural products. Informatization is a significant feature of the e-commerce era, and information technology capability refers to the ability to understand, acquire and utilize information and the ability to use information technology. This paper reflects the level of enterprise information technology capability through five indicators: timely information transmission rate, accurate information transmission rate, information coverage rate, information sharing degree, and technology compatibility.

\section{Analysis of Results}

4.1. Marketing Model Analysis. The percentage of all marketing nodes in the wireless sensor network for each type of operation status is counted to obtain the network security posture value. Marketing nodes that match one of the 15 categories of normal operation data are considered as normal operation marketing nodes, marketing nodes that match one of the 3 categories of abnormal operation data are considered as abnormal operation marketing nodes, and marketing nodes that are not categorized or have missing data are categorized as uncertain states. A total of 11 groups are tested in this experiment, and the intensity of attacks on 
TABLE 1: Marketing evaluation index system.

\begin{tabular}{lccc}
\hline Index number & First-level indicator & Second-level indicator & Third-level indicator \\
\hline & Financial capability & Return on assets & Current ratio \\
& & Asset turnover rate & Customer complaint rate \\
& Operating income growth rate & Customer complaint handling rate \\
& Customer service ability & Cold chain distribution accuracy & The freshness of agricultural products \\
& & One rate of cold chain distribution & The time rate of information delivery \\
& & Logistics service integration & Information transmission accuracy \\
& Information technology capabilities & Information coverage & Technical compatibility \\
& Information sharing degree & The utilization rate of refrigerated trucks \\
\hline
\end{tabular}

marketing nodes varies in different test groups. The relationship between the security posture value of the wireless sensor network and the percentage of attacked marketing nodes in the network is shown in Figure 2.

As the attack frequency increases, the threat posture distance is shown in Figure 3. From the table, we can billion see that the threat level of the network posture gradually increases as the attack frequency increases, the posture distance to the security state gradually increases, the threat of Smurf attack gradually increases, the posture distance to the Smurf attack decreases, and the posture of the rest of the attacks remains unchanged. The experimental results are consistent with expectations and show that the model can correctly sense the threat of wireless sensor networks. In the case of an attack rating of 10, the lowest attack strength is 0.0043 , and in the case of an attack rating of 100 , the lowest attack strength is 0.2897 .

The results of this experiment are compared with the traditional security assessment model for wireless sensor networks based on security chow, which uses network security drops to calculate the overall security level of the route and to describe the security quantitatively. As shown in Figure 4, the horizontal coordinate is the network attack intensity and the vertical coordinate is the network security posture value. The solid line indicates the change of threat level with attack intensity measured by the threat posture awareness method based on cluster analysis, and the dashed line indicates the change of threat level with attack intensity measured by the method based on security bet. According to the comparison results, when the attack frequency is less than 5 times/10s, the trend of the results measured by the model proposed in this paper and the evaluation method based on security bribe is the same, and when the attack frequency is greater than 12 times/10s, the When the attack frequency is greater than 12 times/10s, the proposed method is more sensitive to the change of network threat intensity.

4.2. Marketing System Analysis. Figure 5 visualizes the network throughput of the three algorithms at different data sending rates of the marketing nodes. When the data transmission rate of marketing nodes is below $36 \mathrm{ppm}$, the network throughputs of the three algorithms are similar in size, indicating that all three algorithms can effectively solve the network congestion and meet the network data trans- mission requirements at this time. When the sending rate of marketing nodes is greater than $40 \mathrm{ppm}$, the network throughput under the action of the CCBDC-RSUL algorithm is significantly higher than that of STCP and COMUT congestion control algorithms, which is because the CCBDC-RSUL algorithm adopts effective intracluster and intercluster congestion control strategies based on double cluster heads, LEMPT, the nonuniform hierarchy of target areas and resource scheduling, and the throughput can be maintained with the increase of marketing node sending rate increases and still maintains network stability and also ensures network fairness, while the other two algorithms use measures such as reducing the marketing node data sending rate and AIMD-dropping cache queue packets to reduce network data transmission traffic, resulting in decreasing throughput.

Figure 6 shows the variation and comparison of the network packet transmission delay under each of the three congestion control strategies, COMUT, STCP, and CCBDCRSUL, for different marketing node transmission rates. When the sending rate of marketing nodes is less than $40 \mathrm{ppm}$, the network transmission delay under the effect of CCBDC-RSUL is larger than the other two algorithms, mainly because the CCBDC-RSUL algorithm has to find the subcluster head within the cluster or hierarchically layer the network between clusters and wake up the dormant marketing nodes and establish the lowest energy consumption path tree LEMPT, while the other two algorithms do not need any operation, so the network transmission delay under the effect of CCBDC-RSUL is larger than the other two algorithms. RSUL algorithm acts as a network transmission delay is greater than the other two algorithms. When the sending rate of marketing nodes is greater than $40 \mathrm{ppm}$, the CCBDC-RSUL algorithm has completed the work of intracluster CCBDC and intercluster RSUL, and the lowest energy consumption path tree LEMPT not only reduces the network energy consumption but also ensures the data transmission rate, so it appears that the network data transmission delay under the action of CCBDC-RSUL algorithm is significantly lower than the other two cluster congestion control algorithms Therefore, it appears that the network data transmission delay under the action of CCBDC-RSUL algorithm is significantly lower than the other two clustered congestion control algorithms. 


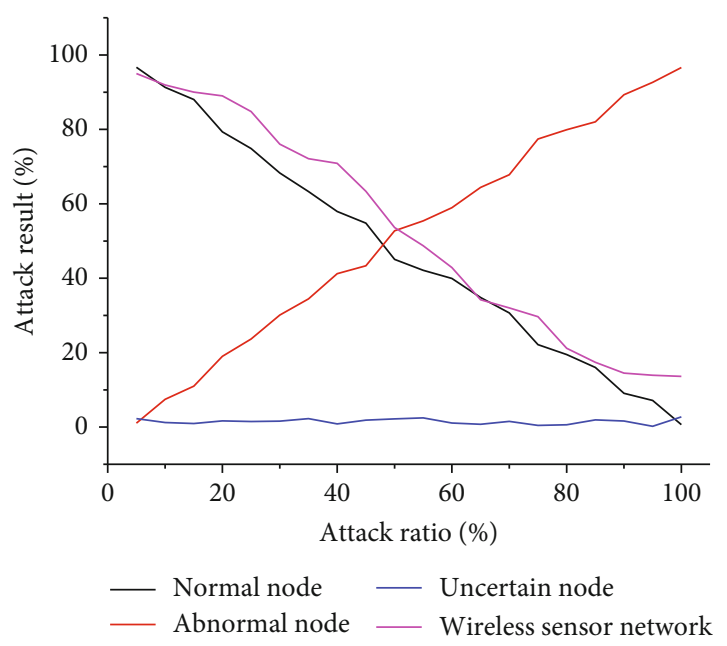

Figure 2: Security posture vs. attack strength.

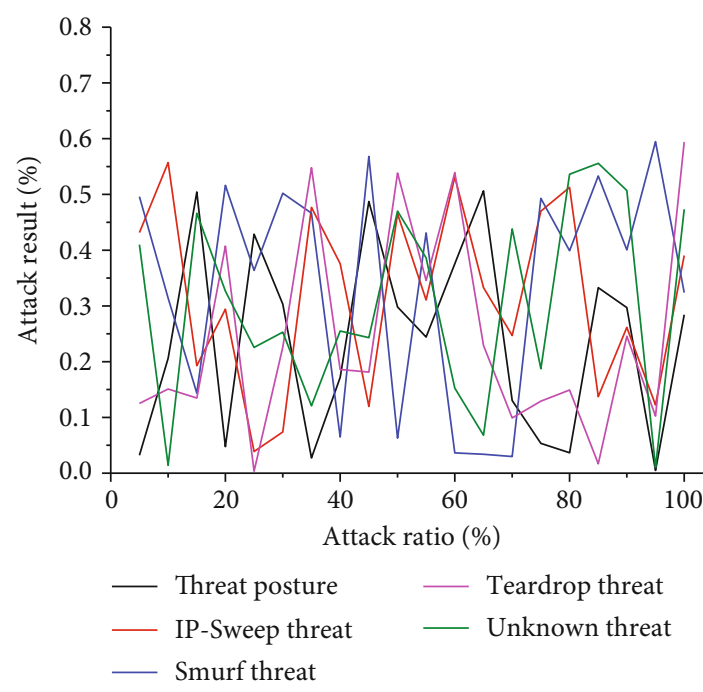

Figure 3: Threat posture and attack intensity relationship.

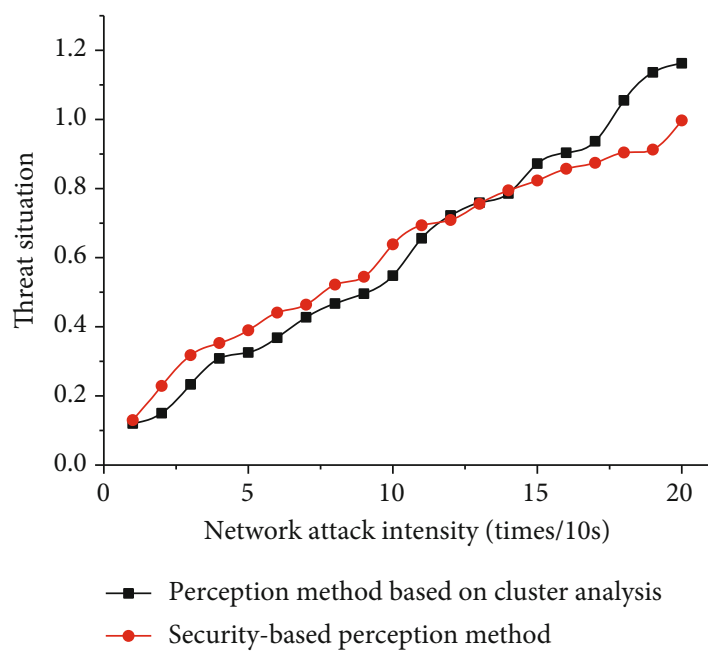

FIGURE 4: Comparison of the results of the cluster analysis method and security entropy method.

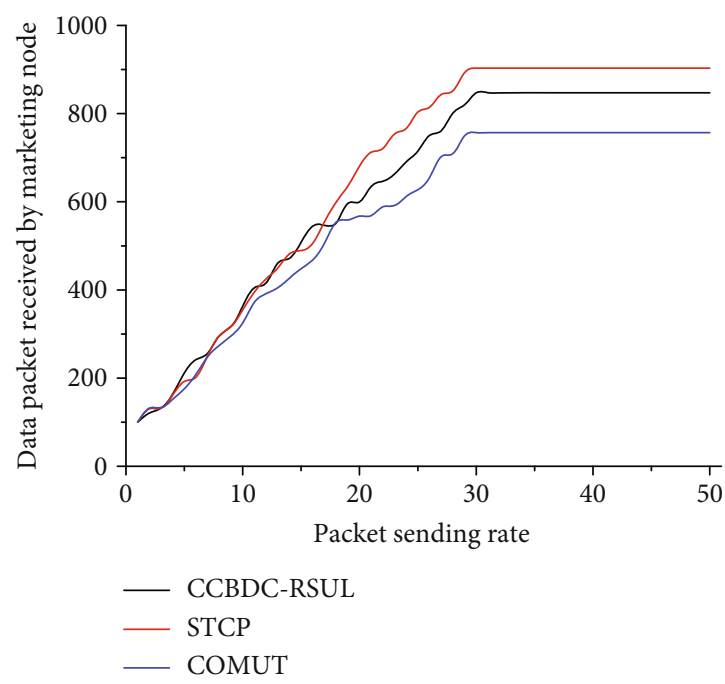

FIgURE 5: Network throughput at different data sending rates.

4.3. Marketing Evaluation Analysis. The overall marketing evaluation results are shown in Figure 7. According to the marketing evaluation criteria, we know that the overall comprehensive marketing of the Company is 82.7961 , which is at the "good" level, but there are still some problems and shortcomings under the good level. From the score of comprehensive marketing evaluation of the first-level indicators, although the cold supply chain capability of the company has the greatest weight in the marketing evaluation, the comprehensive marketing evaluation score is the lowest in the "average" level, which seriously affects the overall marketing level of the company; the comprehensive marketing of the company's financial capability is also not very optimistic; also, this is mainly due to the fact that cold chain logistics requires a large amount of capital investment; the comprehensive marketing of customer service ability belongs to the "good" level, which reflects the importance the company attaches to customer service, but it is still a long way. There is still much room for improvement from achieving "excellent" level; the highest score of comprehensive marketing of information technology capability reflects the characteristics of the e-commerce era and the company's attention to it, but it has not broken the upper limit of good to reach excellent level; the comprehensive marketing of enterprise development capability has a relatively high score of "good "level, indicating that the potential for future development of the company is large, but still needs to continue to check the gaps and strengthen the development of all aspects of the company to meet the needs of the increasingly fierce market competition.

The results of the fuzzy comprehensive evaluation are shown in Figure 8. According to the principle of maximum affiliation in the fuzzy comprehensive evaluation method, the company's operating income growth rate and total capital turnover ratio are at a good level, indicating that the enterprise's finance is in a normal state; however, the total assets return ratio is at an average level and the current ratio belongs to a poor level, indicating that Company profitability is limited at this stage, resulting in the company's weak 


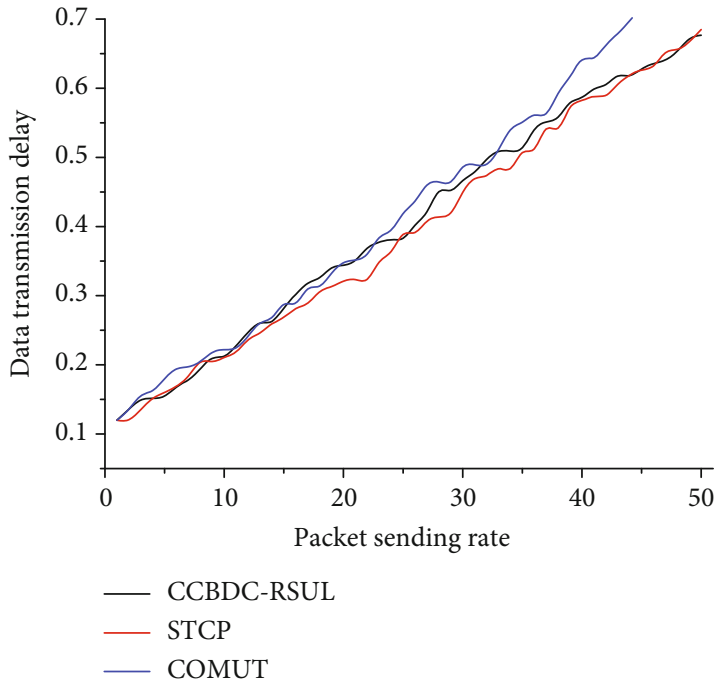

Figure 6: Transmission delay of the three algorithms at different rates.

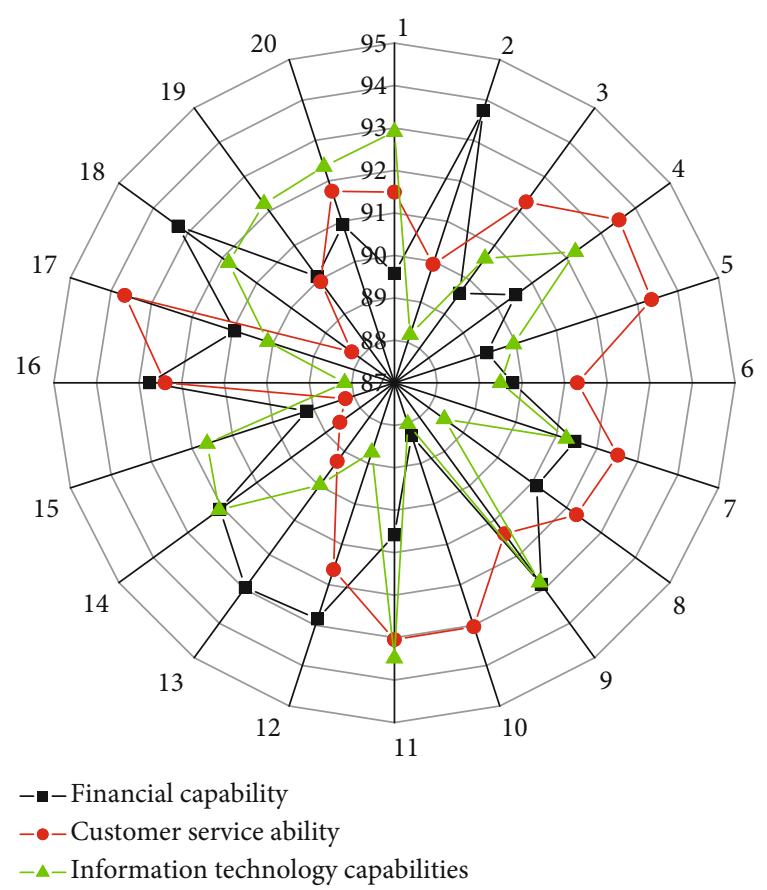

FIGURE 7: Marketing evaluation results.

solvency. The company is still in the early stage of development and needs a lot of capital for expansion, so the dilemma of losing money will continue. Therefore, the marketing level in terms of financial capability is average.

e-Commerce on the cold chain logistics requirements are high, multimodal transport is also driven by this demand came into being, it is to promote the rapid development of economic and trade, reduce transport costs, and accelerate the speed of cargo turnover is significant. The emergence of refrigerated containers, the promotion, and application of a large number of related technology research and development, for the rapid development of cold chain logistics

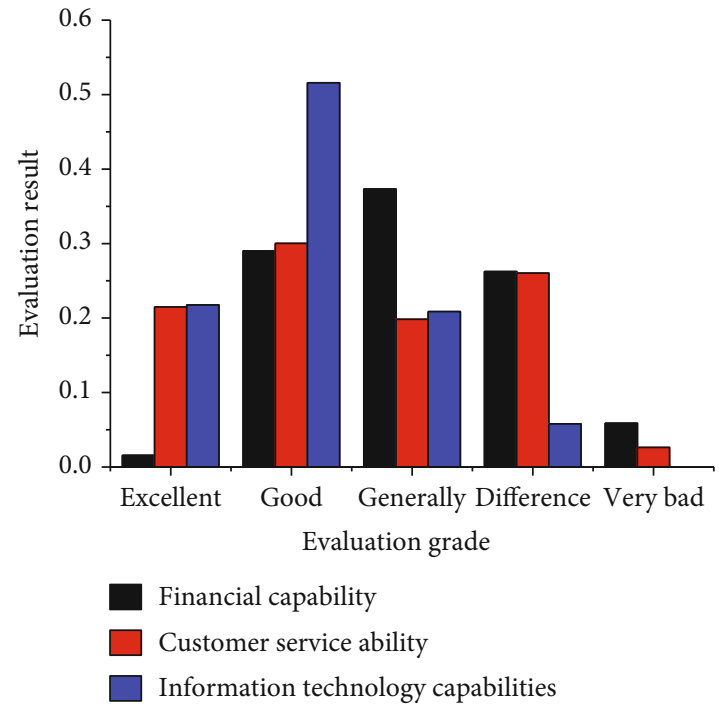

Figure 8: Fuzzy comprehensive evaluation results.

enterprises multimodal transport, to provide protection, but to truly establish a complete multimodal transport system, but also need to accelerate the expansion and improve the waterway transport, railroad transport, air transport, road transport intermodal information network. In addition, the vehicle loading and unloading, handover, rest, and other stopping time generated in the transportation process should also be included in the enterprise marketing assessment, and any possible loss link should be strictly investigated by timely supervision to reduce losses and improve the efficiency of cold supply chain operation as much as possible.

\section{Conclusion}

The application of wireless sensor networks in e-commerce marketing systems will have a large number of nodes, high node density, and uneven node density distribution. In this paper, we calculate and set the cluster head residual energy threshold based on the node energy consumption model to reduce the number of times of cluster selection in the whole network of cluster selection strategy. The nodes are unevenly distributed within the cluster, the cluster area is divided, and the ideal cluster head node that minimizes the cluster energy consumption is found by the node density in different areas and the original cluster head is replaced. According to the minimum energy consumption of the network, the ideal number of cluster heads in different node density intervals is found $\mathrm{K}$. The LEACH routing protocol is improved and designed by the above three strategies to obtain the LEACH-NC routing protocol applicable to specific applications. The effectiveness of the algorithm is demonstrated through simulation experiments. In the application of ecommerce marketing systems, WSN nodes are densely distributed and large in number and combined with the ecommerce operation condition; there is a surge of data traffic of networks collecting e-commerce marketing information in certain periods. Cluster head nodes and prone to node- 
level congestion, the intracluster congestion is relieved and lifted by the dual-cluster head strategy of selecting subcluster heads within a cluster. The nodes near the base station are almost responsible for relaying the data of the whole network, based on getting into link-level congestion, and congestion relief is achieved through a resource scheduling strategy of sharing the pressure of data relaying by waking up the dormant nodes near the congested nodes through the nonuniform layering of network areas. A minimum energy consumption multihop path tree is designed, which can achieve the lowest energy consumption of the source node and the network. In future research, more data and information feedback will be obtained by establishing targeted data models and designing feasible data analysis and data mining algorithms for deeper analysis and mining of data to provide users with more and more accurate quantitative reference information. By establishing a targeted data model, designing feasible data analysis and data mining algorithms, performing deeper tomographic analysis and mining of data, obtaining more data and information feedback, and providing users with more and more accurate quantitative reference information.

\section{Data Availability}

The data used to support the findings of this study are available from the corresponding author upon request.

\section{Conflicts of Interest}

The author declares that he has no known competing financial interests or personal relationships that could have appeared to influence the work reported in this paper.

\section{Acknowledgments}

The study was funded by the research on soft science research project of Henan Province in 2019: Studies on poverty alleviation through rural e-commerce in Henan Province (Project Reference 192400410215).

\section{References}

[1] L. Kang, Y. Chu, K. Leng, and I. van Nieuwenhuyse, "Construction of fast retrieval model of e-commerce supply chain information system based on Bayesian network," Information Systems and e-Business Management, vol. 18, no. 4, pp. 705$722,2020$.

[2] Q. Zhou, Z. Zhang, and Y. Wang, "Research on safety management system optimization of B2C E-commerce intelligent logistics information system based on data cube," Journal of Intelligent \& Fuzzy Systems, vol. 38, no. 2, pp. 1585-1592, 2020.

[3] Y. Xiang, "Set self-service sales and online customization in one of the product network marketing system construction and management research," Cluster Computing, vol. 22, no. S4, pp. 8803-8809, 2019.

[4] Y. Wang, "Bottleneck and countermeasures of cross-border Ecommerce enterprises in coastal cities with application of big data technology," Journal of Coastal Research, vol. 103, no. sp1, pp. 705-708, 2020.

[5] D. Malhotra and O. Rishi, “An intelligent approach to design of E-commerce metasearch and ranking system using nextgeneration big data analytics," Journal of King Saud University-Computer and Information Sciences, vol. 33, no. 2, pp. 183-194, 2021.

[6] C. Horick, "Industry 4.0 production networks: cyber-physical system-based smart factories, real-time big data analytics, and sustainable product lifecycle management," Journal of Self-Governance and Management Economics, vol. 8, no. 1, pp. 107-113, 2020.

[7] C. E. Ocloo, H. Xuhua, S. Akaba, J. Shi, and D. K. WorwuiBrown, "The determinant factors of business to business (B2B) E-commerce adoption in small- and medium-sized manufacturing enterprises," Journal of Global Information Technology Management, vol. 23, no. 3, pp. 191-216, 2020.

[8] G. V. Manohar, B. Bhattacharjee, and M. Pratap, "Preventing misuse of discount promotions in e-commerce websites: an application of rule-based systems," International Journal of Services Operations and Informatics, vol. 11, no. 1, p. 54, 2021.

[9] K. M. Nahiduzzaman, M. Holland, S. K. Sikder, P. Shaw, K. Hewage, and R. Sadiq, "Urban transformation toward a smart city: an E-commerce-induced path-dependent analysis," Journal of Urban Planning and Development, vol. 147, no. 1, 2021.

[10] S. Zhao, Y. Fang, W. Zhang, and H. Jiang, "Trust, perceived benefit, and purchase intention in C2C E-commerce," Journal of Global Information Management, vol. 28, no. 1, pp. 121$141,2020$.

[11] X. Liu and J. Walsh, "Study on development strategies of fresh agricultural products e-commerce in China," International Business Research, vol. 12, no. 8, pp. 61-70, 2019.

[12] Q. Gao, S. Guo, X. Liu, G. Manogaran, N. Chilamkurti, and S. Kadry, "Simulation analysis of supply chain risk management system based on IoT information platform," Enterprise Information Systems, vol. 14, no. 9-10, pp. 1354-1378, 2020.

[13] C. Liu, Y. Xiao, V. Javangula, Q. Hu, S. Wang, and X. Cheng, "Normachain: a blockchain-based normalized autonomous transaction settlement system for IoT-based e-commerce," IEEE Internet of Things Journal, vol. 6, no. 3, pp. 4680-4693, 2019.

[14] Q. Yuan, "The construction mechanism and algorithm of cross border E-commerce export logistics mode from the perspective of value chain," Journal of Intelligent \& Fuzzy Systems, vol. 37, no. 3, pp. 3393-3400, 2019.

[15] M. Zheng, H. Feng, and G. Tian, "The construction and evaluation of green logistics ecosystem of E-commerce in China," Ekoloji, vol. 28, no. 107, pp. 3979-3990, 2019.

[16] A. S. Alkhalfan, Z. W. Altheeb, N. A. Alshamsi et al., "Designing and developing of E-commerce website for unused new goods shopping," International Journal of Scientific Research in Science and Technology, vol. 7, no. 2, pp. 215-225, 2020.

[17] S. Zhang, H. Zhang, and L. Song, "Beyond D2D: Full dimension UAV-to-everything communications in 6G," IEEE Transactions on Vehicular Technology, vol. 69, no. 6, pp. 6592-6602, 2020.

[18] H. Ping, J. Wang, Z. Ma, and Y. Du, "Mini-review of application of IoT technology in monitoring agricultural products quality and safety," International Journal of Agricultural and Biological Engineering, vol. 11, no. 5, pp. 35-45, 2018. 
[19] A. Mohd, R. A. Rashid, A. H. F. A. Hamid et al., "Development of android-based apps for courier service management," Indonesian Journal of Electrical Engineering and Computer Science, vol. 15, no. 2, pp. 1027-1036, 2019.

[20] L. Custodio and R. Machado, "Flexible automated warehouse: a literature review and an innovative framework," The International Journal of Advanced Manufacturing Technology, vol. 106, no. 1-2, pp. 533-558, 2020.

[21] Y. Jaghbeer, R. Hanson, and M. I. Johansson, "Automated order picking systems and the links between design and performance: a systematic literature review," International Journal of Production Research, vol. 58, no. 15, pp. 4489-4505, 2020 . 